Experimental Studies 


\title{
Mismatch Repair Polymorphisms as Markers of Breast Cancer Prevalence in the Breast Cancer Family Registry
}

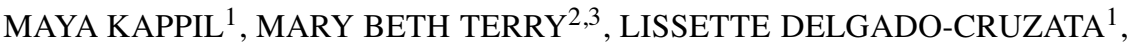 \\ YUYAN LIAO $^{2}$ and REGINA M. SANTELLA ${ }^{1,3}$ \\ Departments of ${ }^{1}$ Environmental Health Sciences and ${ }^{2}$ Epidemiology, \\ Mailman School of Public Health, Columbia University, New York, NY, U.S.A.; \\ ${ }^{3}$ Herbert Irving Comprehensive Cancer Center, Columbia University Medical Center, New York, NY, U.S.A.
}

\begin{abstract}
Background: Major breast cancer susceptibility genes involved in DNA repair, including BRCA1 and BRCA2, have been identified. However, mutations in these genes account for only 5-10\% of identified breast cancer cases. Additional DNA repair pathway genes may also contribute to susceptibility. Materials and Methods: We investigated the association between 12 single nucleotide polymorphisms (SNPs) in mismatch repair (MMR) genes and breast cancer risk among 313 sister-sets enrolled in the New York site of the Breast Cancer Family Registry (BCFR) ( $n=744)$ using conditional logistic regression analysis. Results: An increase in breast cancer risk was observed for women with the MUTYH_rs3219489 variant allele (odds ratio $(O R)=2.23,95 \%$ confidence interval $(C I)=1.10-4.52)$ and for women with the MSH2_rs2303428 variant allele $(O R=1.73$, 95\% CI=1.00-2.99). Conclusion: Deficiencies in DNA repair pathways, such as MMR, have implications for the onset of familial breast cancer.
\end{abstract}

While double strand break (DSBR)-targeted damage, such as chromosomal aberrations, constitute the type of genomic instability most frequently associated with breast cancer risk, susceptibility to substrates targeted by other repair pathways may also confer risk. In addition to DSBR, $B R C A l$ is also associated with a genome surveillance complex that includes mismatch repair (MMR) proteins to sensor and repair replicationassociated DNA damage that has escaped the DNA polymerase proof-reading mechanism (1). These types of damage include

This article is freely accessible online.

Correspondence to: Maya Kappil, One Gustave Levy Place, Box 1057, New York, NY 10029, U.S.A. Tel: +1 2128247350, e-mail: maya.kappil@mssm.edu

Key Words: Breast cancer, mismatch repair, single nucleotide polymorphisms, family history. point mutations that result from single base mismatches following the incorrect incorporation of a nucleotide, as well as frame-shift mutations that occur through errors in the number of bases incorporated at repetitive sequences, resulting in insertions and deletions (IDLs). Such slippages are prone to occur in regions containing microsatellites, simple repeat sequences scattered throughout the genome. Hence, defects in MMR are commonly identified through detection of alterations in the number of such repeats (2).

Microsatellite instability (MSI)-generating defects may be an early event in carcinogenesis that confers a mutator phenotype by inducing genomic instability, thereby enabling the acquisition of additional mutations necessary for tumor progression (3). Studies have already shown increased levels of MSI within tumors, including breast, compared to normal tissues derived from the same individual, implicating defective MMR with breast cancer $(4,5)$. Furthermore, in a study including 30 breast cancer patients, all cases with point mutations in either $M L H 1$ or $M S H 2$, two MMR genes, exhibited increased MSI in tumor versus control tissue, indicating that such sequence variations in MMR genes may play a role in breast cancer risk (6).

However, associations between MMR defects and breast cancer in case-control studies have been inconsistent (7). This may be attributable to the fact that many studies conducted thus far are population-based consisting of women at relatively low risk. Studies focusing on families with a history of breast cancer may be more likely to reveal an association due to the heightened risk present among individuals in this population. Additionally, significant findings in family-based studies are more likely to be indicative of a causal relationship as studies among unrelated individuals may be prone to spurious associations in the presence of underlying differences in both allele and disease frequency.

To further examine the implications of deficiencies in the MMR pathway on the onset of familial breast cancer, we selected MMR-related single nucleotide polymorphisms 
Table I. Candidate mismatch repair (MMR) single nucleotide polymorphisms (SNPs) selected for analysis.

\begin{tabular}{|c|c|c|c|c|}
\hline Gene & dbSNP ID & NCBI Accession No. & Polymorphic nucleotide [amino acid] change & Life Technologies Assay No. \\
\hline MLH1 & rs1799977 & NM_000249.2 & $715 \mathrm{~A}>\mathrm{C}[\mathrm{I} 219 \mathrm{~V}]$ & C_1219076_20 \\
\hline MLH1 & rs 1800734 & NM_000249.3 & $106 \mathrm{G}>\mathrm{A}$ & C_7535141_1_ \\
\hline$M L H 1$ & rs2286940 & NG_007109.1 & $40128 \mathrm{C}>\mathrm{T}$ & C__16181046_10 \\
\hline$M L H 3$ & rs175080 & NM_001040108.1 & $2531 \mathrm{C}>\mathrm{T}[\mathrm{P} 844 \mathrm{~L}]$ & C_1082805_10 \\
\hline MSH2 & rs2303428 & NG_007110.1 & 78238T $>\mathrm{C}[\mathrm{IVS} 12-6 \mathrm{~T}>\mathrm{C}]$ & C__11804019_1_ \\
\hline MSH3 & rs26279 & NM_002439.3 & $3133 \mathrm{G}>\mathrm{A}[\mathrm{T} 1048 \mathrm{~A}]$ & C_800002_1_ \\
\hline MSH3 & rs184967 & NM_002439.2 & $2846 \mathrm{G}>\mathrm{A}[\mathrm{R} 952 \mathrm{Q}]$ & C_907914_10 \\
\hline MSH3 & rs863221 & NG_007109.1 & $40128 \mathrm{C}>\mathrm{T}$ & C___3103297_10 \\
\hline MSH4 & rs5745325 & NM_002440.2 & $289 \mathrm{G}>\mathrm{A}[\mathrm{A} 97 \mathrm{~T}]$ & C_3286081_30 \\
\hline MSH4 & rs5745549 & NM_002440.2 & $2741 \mathrm{G}>\mathrm{A}[\mathrm{N} 914 \mathrm{~S}]$ & C_1184803_10 \\
\hline MSH6 & rs3136228 & NG_007111.1 & $4531 \mathrm{~T}>\mathrm{G}$ & C__28985526_10 \\
\hline MUTYH & rs3219489 & NM_001128425.1 & $1014 \mathrm{G}>\mathrm{C}[\mathrm{H} 335 \mathrm{Q}]$ & C_27504565_10 \\
\hline
\end{tabular}

OR, Odds ratio; CI, confidence interval.

(SNPs) based on the following criteria: a) Significant association with cancer risk ( $p$-value $<0.05)$ reported in epidemiologic studies; b) Minimum $5 \%$ minor allele frequency in Caucasians; or c) Missense mutation incurred by presence of polymorphism in the coding region with minimum $1 \%$ minor allele frequency in Caucasians. Based on these criteria, 12 variants were selected to determine the association between MMR-related defects and breast cancer susceptibility in a family-based case-control study among sisters discordant for breast cancer enrolled in the New York site of the Breast Cancer Family Registry (BCFR).

\section{Materials and Methods}

Study population. We selected participants enrolled in the New York site of the BCFR with available DNA (8-18). Enrollment eligibility for participants in the parent study included having to meet one of the following criteria: i) A female relative who had been diagnosed with either breast or ovarian cancer prior to the age of 45 ; ii) A female relative who has been diagnosed with breast and ovarian cancer at any age; iii) Two or more female relatives who had been diagnosed with breast or ovarian cancer after the age of 45 ; iv) A male relative diagnosed with breast cancer at any age; v) A known carrier of $B R C A 1$ or 2 mutation. We used data collected at baseline through epidemiologic and family history questionnaires on demographics, ethnicity, history of all cancers, smoking, alcohol consumption, reproductive history, hormone use, height, weight, physical activity and dietary intake. Blood was collected at the time of recruitment, on average 5 years after diagnosis of cases (19). The current study includes 313 sister-sets $(n=744)$ consisting of sisters discordant for breast cancer.

Laboratory methods. We extracted DNA from white blood cells (WBCs) using Flexigene DNA kits following the manufacturer's instructions (Qiagen, Valencia, CA, USA). DNA concentration and quality was determined using a NanoDrop ND-1000 spectrophotometer (Thermo Scientific, Wilmington, DE, USA).

Genotyping was carried out using Taqman allele discrimination assays (Life Techologies, Carlsbad, CA, USA). Real-time polymerase chain reaction (PCR) was carried out in $5 \mu$ reactions containing 5 ng genomic DNA, 1X SNP Genotyping Assay Mix and 1X Taqman Universal PCR Mastermix. The PCR thermocycling protocol consisted of $95^{\circ} \mathrm{C}$ for $10 \mathrm{~min}$, followed by 45 cycles of $95^{\circ} \mathrm{C}$ for $15 \mathrm{~s}$ and $60^{\circ} \mathrm{C}$ for $90 \mathrm{~s}$. Assays were conducted in a 7900 Real-time PCR platform (Life Technologies); allelic discrimination software was provided by the manufacturer. Each plate contained non-template controls and $10 \%$ of the samples were re-assayed to determine concordance. A call rate of greater than $95 \%$ was observed for all assays. All laboratory personnel involved in sample handling were blinded to case status.

Statistical analysis. Hardy-Weinberg equilibrium was tested to assess deviations of observed from expected genotype frequencies among cases and controls. We used conditional logistic regression to determine odds ratios (ORs) and 95\% confidence intervals (CIs) associating individual queried genotypes with breast cancer risk. Due to the low frequency of homozygous carriers of the variant allele for some of the SNPs assayed, each SNP was also analyzed upon combining heterozygous and homozygous carriers of the variant allele. As age at blood draw and smoking status are linked to breast cancer onset, both factors were adjusted for in the final multivariable conditional logistic regression model. All analyses were performed using Statistical Analysis System version 9.4 (SAS Institute, Cary, NC, USA).

\section{Results}

As shown in Table I, seven of the 12 SNPs we assayed are located within exons in which the presence of the variant allele induces a non-synonymous amino acid alteration. Two of the selected SNPs (MLH1_1800734 and MSH6_rs3136228) are located upstream of the transcription start site (TSS), whereas the remaining three SNPs are located in introns (MLH1_rs1799977, MSH2_rs2303428 and MSH3_rs863221).

Several of the tested SNPs deviated significantly from the Hardy-Weinberg (HW) equilibrium (MLH1_rs1799977, $p=0.01$, MLH1_rs2286940, $p<0.01$, MSH4_rs5745325, $p=0.03$ ) (Table I). This is not surprising since the presence of 
Table II. Association between mismatch repair (MMR) genotype and breast cancer risk.

\begin{tabular}{|c|c|c|c|c|c|}
\hline Gene & dbSNP ID & Genotype & Affected sister No. (\%) & Unaffected sister No. (\%) & OR* $(95 \% \mathrm{CI})$ \\
\hline \multirow[t]{12}{*}{$M L H 1$} & \multirow[t]{4}{*}{ rs 1799977} & AA & $183(55.3)$ & $226(55.8)$ & 1.0 (Ref) \\
\hline & & $\mathrm{AG}$ & $118(35.6)$ & $143(35.3)$ & $1.07(0.67-1.70)$ \\
\hline & & GG & $30(9.1)$ & $36(8.9)$ & $1.00(0.46-2.14)$ \\
\hline & & $\mathrm{AG} / \mathrm{GG}$ & $148(44.7)$ & $179(44.2)$ & $1.07(0.67-1.69)$ \\
\hline & \multirow[t]{4}{*}{ rs 1800734} & GG & $178(53.6)$ & $224(55.2)$ & $1.0(\mathrm{Ref})$ \\
\hline & & GA & $131(39.5)$ & $154(37.9)$ & $0.99(0.67-1.51)$ \\
\hline & & AA & $23(6.9)$ & $28(6.9)$ & $1.07(0.49-2.32)$ \\
\hline & & GA/AA & $154(46.4)$ & $182(44.8)$ & $1.00(0.66-1.51)$ \\
\hline & \multirow[t]{4}{*}{ rs2286940 } & $\mathrm{CC}$ & $135(40.7)$ & $164(40.4)$ & $1.0(\mathrm{Ref})$ \\
\hline & & $\mathrm{CT}$ & $133(40.1)$ & $168(41.4)$ & $0.97(0.61-1.54)$ \\
\hline & & $\mathrm{TT}$ & $64(19.3)$ & $74(18.2)$ & $1.08(0.58-2.00)$ \\
\hline & & $\mathrm{CT} / \mathrm{TT}$ & $197(59.4)$ & $242(59.6)$ & $0.99(0.63-1.56)$ \\
\hline \multirow[t]{4}{*}{$M L H 3$} & \multirow[t]{4}{*}{ rs 175080} & GG & $104(31.9)$ & $111(27.4)$ & $1.0(\mathrm{Ref})$ \\
\hline & & GA & $158(48.5)$ & $207(51.1)$ & $0.69(0.45-1.08)$ \\
\hline & & AA & $64(19.6)$ & $87(21.5)$ & $0.60(0.33-1.10)$ \\
\hline & & GA/AA & $222(68.1)$ & $294(72.6)$ & $0.68(0.44-1.05)$ \\
\hline \multirow[t]{4}{*}{ MSH2 } & \multirow[t]{4}{*}{ rs2303428 } & TT & $242(75.6)$ & $310(78.1)$ & $1.0(\operatorname{Ref})$ \\
\hline & & $\mathrm{TC}$ & $77(24.1)$ & $81(20.4)$ & $1.73(1.00-3.00)$ \\
\hline & & $\mathrm{CC}$ & $1(0.3)$ & $6(1.5)$ & \\
\hline & & $\mathrm{TC} / \mathrm{CC}$ & $78(24.4)$ & 87 (21.9) & $1.73(1.00-3.00)$ \\
\hline \multirow[t]{4}{*}{ MSH6 } & \multirow[t]{4}{*}{ rs3136228 } & $\mathrm{TT}$ & $164(50.8)$ & $191(47.5)$ & $1.0(\operatorname{Ref})$ \\
\hline & & TG & $118(36.5)$ & $171(42.5)$ & $0.83(0.53-1.32)$ \\
\hline & & GG & $41(12.7)$ & $40(10)$ & $1.44(0.67-3.09)$ \\
\hline & & TG/GG & $159(49.2)$ & $211(52.5)$ & $0.88(0.56-1.38)$ \\
\hline \multirow[t]{12}{*}{ MSH3 } & \multirow[t]{4}{*}{ rs 26279} & $\mathrm{AA}$ & $160(48.2)$ & $185(46.1)$ & $1.0(\mathrm{Ref})$ \\
\hline & & $\mathrm{AG}$ & $143(43.1)$ & $171(42.6)$ & $0.84(0.55-1.26)$ \\
\hline & & GG & $29(8.7)$ & $45(11.2)$ & $0.73(0.37-1.42)$ \\
\hline & & $\mathrm{AG} / \mathrm{GG}$ & $172(51.8)$ & $216(53.8)$ & $0.82(0.55-1.24)$ \\
\hline & \multirow[t]{4}{*}{ rs184967 } & GG & $236(71.7)$ & $285(70.4)$ & $1.0(\mathrm{Ref})$ \\
\hline & & GA & $82(24.9)$ & $111(27.4)$ & $0.76(0.49-1.19)$ \\
\hline & & AA & $11(3.3)$ & $9(2.2)$ & $1.34(0.50-3.58)$ \\
\hline & & GA/AA & $93(28.2)$ & $120(29.6)$ & $0.80(0.51-1.23)$ \\
\hline & \multirow[t]{4}{*}{ rs863221 } & $\mathrm{TT}$ & $149(44.5)$ & $179(44)$ & $1.0(\operatorname{Ref})$ \\
\hline & & TG & $155(46.3)$ & $194(47.7)$ & $0.88(0.60-1.27)$ \\
\hline & & GG & $31(9.3)$ & $34(8.4)$ & $1.02(0.50-2.07)$ \\
\hline & & TG/GG & $186(55.6)$ & $228(56.1)$ & $0.89(0.62-1.28)$ \\
\hline \multirow[t]{8}{*}{ MSH4 } & \multirow[t]{4}{*}{ rs5745325 } & GG & $163(49.4)$ & $199(49)$ & $1.0(\mathrm{Ref})$ \\
\hline & & GA & $131(39.7)$ & $159(39.2)$ & $0.99(0.65-1.50)$ \\
\hline & & $\mathrm{AA}$ & $36(10.9)$ & $48(11.8)$ & $0.89(0.44-1.80)$ \\
\hline & & GA/AA & $167(50.6)$ & $207(51)$ & $0.98(0.65-1.48)$ \\
\hline & \multirow[t]{4}{*}{ rs5745549 } & GG & $292(89.8)$ & $363(89.6)$ & $1.0(\mathrm{Ref})$ \\
\hline & & GA & $33(10.2)$ & $42(10.4)$ & $1.07(0.53-2.18)$ \\
\hline & & AA & $0(0)$ & $0(0)$ & \\
\hline & & GA/AA & & & $1.07(0.53-2.18)$ \\
\hline \multirow[t]{4}{*}{ MUTYH } & \multirow[t]{4}{*}{ rs3219489 } & $\mathrm{CC}$ & $168(50.8)$ & $211(52.4)$ & $1.0(\mathrm{Ref})$ \\
\hline & & CG & $127(38.4)$ & $162(40.2)$ & $1.02(0.67-1.54)$ \\
\hline & & GG & $36(10.9)$ & $30(7.4)$ & $2.23(1.10-4.52)$ \\
\hline & & $\mathrm{CG} / \mathrm{GG}$ & $163(49.3)$ & $192(47.6)$ & $1.14(0.76-1.70)$ \\
\hline
\end{tabular}

*Adjusted for age at blood draw and smoking status.

related individuals in our family-based case-control study population likely results in skewed allele frequencies.

As shown in Table II, the variant MUTYH_rs3219489 allele was associated with a two-fold association with breast cancer risk $(\mathrm{OR}=2.23,95 \% \mathrm{CI}=1.10-4.52)$ after adjusting for age at blood draw and smoking status. Similarly, following adjustment for age at blood draw and smoking status, the variant MSH2_rs2303428 allele was associated with breast cancer risk, upon combining homozygous and heterozygous carriers $(\mathrm{OR}=1.73,95 \% \mathrm{CI}=1.00-2.99)$ (Table II). 


\section{Discussion}

Out of the selected MMR-related SNPs, we observed approximately two-fold associations for two variant alleles, MSH2_rs2303428 and MUTYH_rs3219489, and breast cancer risk within high-risk families. None of the other SNPs we assayed were associated with breast cancer risk. Unlike previous studies, a major strength of the current study is the ability to minimize confounding variables due to population admixture through the use of a family-based case-control study as all comparisons were within-families.

MSH2 is part of the MSH $\alpha$ heterodimer that initiates MMR upon recognition of post-replicative errors. This heterodimer consists of MSH2 complexed with either MSH6 to identify base mismatches and small IDLs or with MSH3 to identify larger IDLs. Similarly, MUTYH also participates in the recognition of mismatches, specifically the mispairing between adenine and 8-oxoguanine. Following the removal of the mispaired adenine, cytosine is correctly incorporated and base excision repair (BER) is initiated to remove the oxidized base and replace it with an intact guanine. As such, MUTYH is classified as a member of both MMR and BER.

Deficiencies in MMR have been most often reported in association with the Lynch syndrome family of cancers, while no clear link between any type of cancer and reduced BER capacity has been established thus far. Though few studies implicate either MMR or BER with breast cancer (20-22), one hospital based case-control study with 287 cases and 547 controls conducted in a Portuguese population has shown an association between SNPs in the MMR pathway and breast cancer risk (23). Contrary to our study, an increase in risk due to either MSH2_rs2303428 or MUTYH_rs3219489 variants was not reported in this study by Conde et al. (23). This is likely due to the inherent differences in the populations interrogated by the respective studies. While our study selected high-risk families, the Portuguese study focused on cases and unrelated controls without a family history of breast cancer.

Although the variants identified in the current study have not been directly implicated with breast cancer, both MSH2_rs2303428 and MUTYH_rs3219489 have been associated with other sites. A case-control study conducted within a Chinese population associated MSH2_rs2303428 with the onset of gastric cancer. Interestingly, the observed effect was restricted to those with a family history of gastric cancer $(\mathrm{OR}=1.68,95 \% \mathrm{CI}=1.27-2.66)$ (24). Fewer studies have implicated a role for MUTYH_rs3219489 in cancer (25). However, a recent colorectal case-control study conducted in Sweden associated the presence of the variant with the onset of rectal cancer (OR=1.52, 95\% CI=1.06-2.17) (26).

While the MUTYH_rs3219489 SNP is located in exon 12 and results in a non-synonymous amino acid change, the MSH2_rs2303428 SNP is located in the intron region between exons 12 and 13. Based on computational analysis and functional assays, this polymorphism has been shown to be located near a splice acceptor site at the exon-intron boundary, with the presence of the variant leading to partial exon 13 skipping, resulting in the translation of an altered protein from the alternatively spliced message (27).

Due to the low frequency of homozygous recessive individuals for the MSH2_rs2303428 SNP, we were not able to assess the risk of breast cancer due to the presence of two variant alleles. However, the borderline association observed in the presence of one or more variant alleles suggests that this allele functions through a dominant model. Hence, the deleterious effect imparted by just one variant allele may also account for the low frequency of individuals with two copies of the variant.

While the presence of two MUTYH rs3219489 variant alleles was associated with an increase in breast cancer risk, the effect was lost upon combining heterozygous and homozygous carriers, suggesting this variant acts through a recessive model. This is in agreement with the findings from the Swedish colorectal case-control study in which the association observed between the presence of two variant MUTYH_rs3219489 alleles and rectal cancer was lost upon combining heterozygous and homozygous carriers of the allele (26).

Numerous SNPs exist across genes involved in the MMR pathway. Hence, although an association with breast cancer was observed with several SNPs, the subset of SNPs selected in this study may have excluded SNPs with potentially greater relevance for breast cancer. Restricting the focus on a choice few targets also results in examining the impact of each SNP in isolation. This approach does not take into account the possibility that the presence of other SNPs may magnify or counteract the impact of the SNP under study. Due to the small sample size of our study, we did not have enough power to assess possible interactions among the variants interrogated. Even if these interactions could have been investigated, we would not have been able to account for the impact of SNPs not interrogated in our study. This can be addressed by genome-wide association studies (GWAS), which, unlike candidate SNPs studies, not only query the entire genome for all SNPs of relevance but can also examine the impact of each SNP in the context of all other known variants across the genome. However, the variants identified in GWAS studies are often of unknown function, complicating the inferences that can be drawn from such findings. This is in contrast to candidate SNP studies as selection of SNPs is informed based on known functional implications of targets in genes and pathways of relevance, facilitating the mechanistic understanding underlying the observed association.

In conclusion, in our family-based case-control study, we observe an increase in breast cancer risk due to alleles typically associated with Lynch syndrome cancers. These findings suggest that, while polymorphisms in MMR have, thus far, not been associated with sporadic breast cancer, deficiencies in this pathway may be relevant in familial breast cancer. 


\section{Acknowledgements}

This work was supported by an award from the Breast Cancer Research Foundation and grants from the National Institutes of Health (ES009089 and CA013696).

\section{References}

1 Wang Y, Cortez D, Yazdi P, Neff N, Elledge SJ and Qin J: BASC, a super complex of BRCA1-associated proteins involved in the recognition and repair of aberrant DNA structures. Genes Dev 14: 927-939, 2000.

2 Parsons R, Li GM, Longley MJ, Fang WH, Papadopoulos N, Jen J, de la Chapelle A, Kinzler KW, Vogelstein B and Modrich P: Hypermutability and mismatch repair deficiency in RER+ tumor cells. Cell 75: 1227-1236, 1993.

3 Loeb LA: Microsatellite instability: marker of a mutator phenotype in cancer. Cancer Res 54: 5059-5063, 1994.

4 Yee CJ, Roodi N, Verrier CS and Parl FF: Microsatellite instability and loss of heterozygosity in breast cancer. Cancer Res 54: 16411644, 1994.

5 Shaw JA, Walsh T, Chappell, SA, Carey N, Johnson K and Walker RA: Microsatellite instability in early sporadic breast cancer. Br J Cancer 73: 1393-1397, 1996.

6 Murata H, Khattar NH, Kang Y, Gu L and Li GM: Genetic and epigenetic modification of mismatch repair genes hMSH2 and hMLH1 in sporadic breast cancer with microsatellite instability. Oncogene 21: 5696-5703, 2002.

7 Barrow E, Hill, J and Evans DG: Cancer risk in Lynch Syndrome. Fam. Cancer 12: 229-240, 2013.

8 Kennedy DO, Agrawal M, Shen J, Terry MB, Zhang FF, Senie RT, Motykiewicz G and Santella RM: DNA repair capacity of lymphoblastoid cell lines from sisters discordant for breast cancer. J Natl Cancer Inst 97: 127-132, 2005.

9 Shen J, Desai M, Agrawal M, Kennedy DO, Senie RT, Santella RM and Terry MB: Polymorphisms in nucleotide excision repair genes and DNA repair capacity phenotype in sisters discordant for breast cancer. Cancer Epidemiol Biomarkers Prev 15: 1614-1619, 2006.

10 Shen J, Terry MB, Gurvich I, Liao Y, Senie RT and Santella RM: Short telomere length and breast cancer risk: a study in sister sets. Cancer Res 67: 5538-5544, 2007.

11 Machella N, Terry MB, Zipprich J, Gurvich I, Liao Y, Senie RT, Kennedy DO and Santella RM: Double-strand breaks repair in lymphoblastoid cell lines from sisters discordant for breast cancer from the New York site of the BCFR. Carcinogenesis 29: 13671372, 2008.

12 Zipprich J, Terry MB, Liao Y, Agrawal M, Gurvich I, Senie R and Santella RM: Plasma protein carbonyls and breast cancer risk in sisters discordant for breast cancer from the New York site of the Breast Cancer Family Registry. Cancer Res 69: 2966-2972, 2009.

13 Zipprich J, Terry MB, Brandt-Rauf P, Freyer GA, Liao Y, Agrawal M, Gurvich I, Senie R and Santella RM: XRCC1 polymorphisms and breast cancer risk from the New York Site of the Breast Cancer Family Registry: A family-based case-control study. J. Carcinog 9: 4, 2010.

14 Delgado-Cruzata L, Wu H, Perrin M, Liao Y, Kappil MA, Ferris JS, Flom JD, Yazici H, Santella RM and Terry MB: Global DNA methylation levels in white blood cell DNA from sisters discordant for breast cancer from the New York site of the Breast Cancer Family Registry. Epigenetics 7: 868-874, 2012.
15 Shen J, Terry MB, Liao Y, Gurvich I, Wang Q, Senie RT and Santella RM: Genetic variation in telomere maintenance genes, telomere length and breast cancer risk. PLoS One 7: e44308, 2012.

16 Wu HC, Delgado-Cruzata L, Flom, JD, Perrin M, Liao, Y, Ferris JS, Santella RM and Terry MB: Repetitive element DNA methylation levels in white blood cell DNA from sisters discordant for breast cancer from the New York site of the Breast Cancer Family Registry. Carcinogenesis 33: 1946-1952, 2012.

17 Delgado-Cruzata L, Wu HC, Liao Y, Santella RM and Terry MB: Differences in DNA methylation by extent of breast cancer family history in unaffected women. Epigenetics 9: 243-248, 2014.

18 Wu HC, Delgado-Cruzata L, Machella N, Wang Q, Santella RM and Terry MB: DNA double-strand break repair genotype and phenotype and breast cancer risk within sisters from the New York site of the Breast Cancer Family Registry (BCFR). Cancer Causes Control 24: 2157-2168, 2013.

19 John EM, Hopper JL, Beck JC, Knight JA, Neuhausen SL, Senie RT, Ziogas A, Andrulis IL, Anton-Culver H, Boyd N, Buys SS, Daly MB, O'Malley FP, Santella RM, Southey MC, Venne VL, Venter DJ, West DW, Whittemore AS and Seminara D: The Breast Cancer Family Registry: an infrastructure for cooperative multinational, interdisciplinary and translational studies of the genetic epidemiology of breast cancer. Breast Cancer Res 6: R375-R389, 2004.

20 Monsees GM, Kraft P, Chanock SJ, Hunter DJ and Han J: Comprehensive screen of genetic variation in DNA repair pathway genes and postmenopausal breast cancer risk. Breast Cancer Res Treat 125: 207-214, 2011.

21 Watson P, Vasen HFA, Mecklin JP, Bernstein I, Aarnio M, Järvinen HJ, Myrhøj T, Sunde L, Wijnen JT, Lynch HT: The risk of extra-colonic, extra-endometrial cancer in the Lynch syndrome. Int J Cancer 123: 444-449, 2008.

$22 \mathrm{Wu}$ B, Liu HL, Zhang S, Dong XR and Wu G: Lack of an association between two BER gene polymorphisms and breast cancer risk: a meta-analysis. PLoS One 7: e50857, 2012.

23 Conde J, Silva, SN, Azevedo, AP, Teixeira V, Pina JE, Rueff J and Gaspar JF. Association of common variants in mismatch repair genes and breast cancer susceptibility: A multigene study. BMC Cancer 9: 344, 2009.

24 Wang D, Zhou J, Wang T, Li X, Li S, Chen S, Ma G, Li J and Zhang Xi: Polymorphisms in MSH2 gene and risk of gastric cancer, and interactions with lifestyle factors in a Chinese population. Cancer Epidemiol 36: e171-e176, 2012.

25 Qian B, Zhang H, Zhang L, Zhou X, Yu H and Chen K: Association of genetic polymorphisms in DNA repair pathway genes with nonsmall cell lung cancer risk. Lung Cancer 73: 138-146, 2011.

26 Picelli S, Zajac P, Zhou XL, Edler D, Lenander C, Dalén J, Hjern F, Lundqvist N, Lindforss U, Påhlman L, Smedh K, Törnqvist A, Holm J, Janson M, Andersson M, Ekelund S, Olsson L, Lundeberg $\mathrm{J}$ and Lindblom A: Common variants in human CRC genes as low-risk alleles. Eur J Cancer 46: 1041-1048, 2010.

27 Tournier I, Vezain M, Martins A, Charbonnier F and BaertDesurmont S: A large fraction of unclassified variants of the mismatch repair genes MLH1 and MSH2 is associated with splicing defects. Hum Mutat 29: 1412-1424, 2008.

Received July 13, 2016

Revised July 19, 2016

Accepted July 20, 2016 